\section{Sobre eventos adversos de la vacuna contra la COVID-19 de Sinopharm}

\section{About Sinopharm COVID-19 vaccine adverse events}

\section{Sr. Editor:}

Luego de la lectura del artículo de Ibañez y cols. ${ }^{1}$, los autores indican que la vacuna de Sinopharm origina diversas manifestaciones locales y sistémicas; sin embargo, no se especifican las frecuencias de dichas manifestaciones.

Desde febrero de 2021 se inició el programa de vacunación del personal sanitario en el Perú ${ }^{2}$. Para dicho personal se ha destinado el antídoto de Sinopharm² ${ }^{2}$. En la presente carta científica reportamos las frecuencias con la que se presentaron los eventos adversos tras la inoculación de la primera dosis de la vacuna de Sinopharm en un grupo de odontólogos peruanos. Los participantes fueron reclutados vía correo electrónico y/o WhatsApp. Se envió un consentimiento informado y un formulario sobre eventos adversos elaborado en base a la directiva sanitaria de

Tabla 1. Eventos adversos tras la aplicación de la vacuna de Sinopharm

\begin{tabular}{lcc}
\hline Evento adverso & Participantes & Porcentajes \\
\hline Dolor* & 116 & $56 \%$ \\
Cefalea & 58 & $28 \%$ \\
\hline Somnolencia & 57 & $27,5 \%$ \\
\hline Fatiga & 32 & $15,4 \%$ \\
\hline Mialgia & 24 & $11,6 \%$ \\
Mareos & 15 & $7,2 \%$ \\
\hline Fiebre temporal & 13 & $6,3 \%$ \\
\hline Diarrea & 11 & $5,3 \%$ \\
\hline Picazón* & 7 & $3,4 \%$ \\
\hline Prurito* & 6 & $2,9 \%$ \\
\hline Artralgia & 5 & $2,4 \%$ \\
Naúseas y vómitos & 4 & $1,9 \%$ \\
\hline Enrojecimiento* & 4 & $1,9 \%$ \\
\hline Endurecimiento* & 4 & $1,9 \%$ \\
\hline Hinchazón* & 2 & $0,9 \%$ \\
\hline Sarpullido* & 1 & $0,5 \%$ \\
\hline Taquicardia & 1 & $0,5 \%$ \\
\hline *En el lugar de aplicación de la vacuna. & & \\
\hline & & \\
\hline
\end{tabular}

Perú N 129-MINSA/2021/DGIESP². Respondieron 207 odontólogos, siendo 143 mujeres y 64 varones con edades entre 20 a 65 años; dos participantes indicaron tener asma, uno cardiopatía congénita, tres hipertensión arterial y 51 padecieron la COVID-19 en los meses previos. Los resultados se exponen en la Tabla 1.

La vacuna de Pfizer-BioNTech reportó cefalea y fatiga como eventos adversos comunes ${ }^{1}$, siendo estos también encontrados en el presente reporte; además, estos dos eventos fueron los de mayor ocurrencia en poblaciones de Medio Oriente inmunizadas con Sinopharm ${ }^{3}$. Por otro lado, la vacuna Sputnik V presentó $58 \%$ de casos con dolor en la zona inoculada ${ }^{1}$. En nuestra experiencia el dolor en dicha zona representó el 56\%; sin embargo, en Baréin y Emiratos Árabes Unidos se ha encontrado dicho síntoma, tras la vacuna de Sinopharm, en solo un $24,3 \%{ }^{3}$. Dicha diferencia podría deberse a que el Perú ha sido uno de los países más azotados por la pandemia, y los odontólogos son, junto con los médicos y enfermeros, los profesionales más vulnerables al contagio y con altos índices de estrés propio de su labor, todo ello podría explicar una mayor susceptibilidad al dolor tras la inoculación. Adicionalmente, en menos del 2\% hubo enrojecimiento e hinchazón local, lo cual también fue encontrado con la vacuna de Sinopharm en Medio Oriente . $^{3}$.

Como evento raro se encontró un caso local de sarpullido, reportado anteriormente con la vacuna de Moderna mRNA-1273 y de Sinopharm, conociéndose a dicho evento como "brazo de COVID-19"3,4. Además, se registró un evento de taquicardia tras la vacunación. Este evento también se encontró con la vacuna de PfizerBioNTech en España y aún no se incluye en sus manuales de farmacovigilancia 5 .

\section{Referencias bibliográficas}

1.- Ibáñez C, Torres J, Santolaya de Pablo M. Vacunas SARSCoV-2, estudios en fase III. Rev Chilena Infectol 2021; 38: 88-98. doi: 10.4067/S0716-10182021000100088.

2.- Ministerio de Salud. Directiva sanitaria para la vacunación contra la Covid-19 en la situación de emergencia sanitaria por la pandemia en el Perú [Internet]. Lima: MINSA; 2021 (Fecha de acceso: 29 de mayo de 2021). Disponible en: https://cdn.www.gob.pe/uploads/document/file/1645872/ Directiva\%20Sanitaria\%20N\%C2\%BA129-MINSA/2021/ DGIESP.pdf

3.- Al Kaabi N, Zhang Y, Xia S, Yang Y, Al Qahtani MM, Abdulrazzaq N, et al. Effect of 2 inactivated SARS-CoV-2 vaccines on symptomatic COVID-19 infection in adults: A randomized clinical trial. JAMA 2021; 326: 35-45. doi: 10.1001/jama.2021.8565.

4.- Wei N, Fishman M, Wattenberg D, Gordon M, Lebwohl M. "COVID arm": A reaction to the Moderna vaccine. JAAD Case Rep 2021; 10: 92-5. doi: 10.1016/j.jdcr.2021.02.014. 


\section{Carta al Editor}

${ }^{1}$ Universidad Nacional Mayor de San Marcos.

Tachycardia as an undescribed adverse effect to the Comirnaty $(\mathbb{C}$ vaccine (BNT162b2 Pfizer-BioNTech Covid-19 vaccine): Description of 3 cases with a history of SARS-CoV-2 disease. Enferm Infecc Microbiol Clin (Engl Ed.) 2021: S0213-005X(21)00074-4. doi: 10.1016/j. eimc.2021.03.008.

Jhon Paul I. Mezarina-Mendoza ${ }^{1}$, María del C. Carrasco-Freitas ${ }^{1}$ y Elías Aguirre-Siancas ${ }^{2}$.
Lima, Perú.
2Universidad Científica del Sur. Lima Perú.

Los autores declaran no tener conflictos de intereses en relación al trabajo presentado.

\section{Correspondencia:}

Elias Aguirre Siancas eaguirre@cientifica.edu.pe 